This PDF is a selection from a published volume from the National Bureau of Economic Research

Volume Title: Hard-to-Measure Goods and Services: Essays in Honor of Zvi Griliches

Volume Author/Editor: Ernst R. Berndt and Charles R. Hulten, editors

Volume Publisher: University of Chicago Press

Volume ISBN: 0-226-04449-1; 978-0-226-04449-1

Volume URL: http://www.nber.org/books/bern07-1

Conference Date: September 19-20, 2003

Publication Date: October 2007

Title: Technology and the Theory of Vintage Aggregation Author: Michael J. Harper

URL: http://www.nber.org/chapters/c0875 


\title{
Technology and the Theory \\ of Vintage Aggregation
}

\author{
Michael J. Harper
}

I only want to urge that research not get tied to any one particular picture of the way the economy functions.

-Robert Solow (2001)

\subsection{Introduction}

When vintage investments are aggregated into "capital stocks," rigid assumptions are made about the effects of technology. This can limit the usefulness of capital stock measures. Vintage aggregation issues were the subject of a vigorous literature in the 1950s and 1960s, and Zvi Griliches (1963) was an active participant in these discussions. By the 1970s, many economists considered these issues to be resolved, and they have received less attention in recent decades. The acceleration of information processing and communications technologies in the 1990s, however, may increase the potential for bias in capital stock measures. This accelerating technological progress has had many ramifications for economic measurement in the United States. Our National Income and Product Accounts did not account for the quality change in computers until Jack Triplett (1989) proposed adjusting Computer Price Indexes for quality change with hedonic methods. As Charles Hulten (1992) observed, the Triplett treatment identifies quality change with embodied technical change, as Robert Hall (1968) had defined it. Once these hedonic methods were in place, growth

Michael J. Harper is Associate Commissioner for Productivity and Technology at the Bureau of Labor Statistics.

The views expressed are those of the author and do not necessarily reflect the policies of the U.S. Bureau of Labor Statistics or the views of other staff members. An early draft of this paper was presented at the NBER Summer Institute in 1999, where Zvi Griliches made helpful comments. I would also like to acknowledge Anthony Barkume, Ernst Berndt, Carol Corrado, Edwin Dean, W. Erwin Diewert, Murray Foss, Robert Gordon, Charles Hulten, Marilyn Manser, Peter Meyer, Linda Moeller, Phyllis Otto, Sabrina Pabilonia, Matthew Shapiro, Daniel Sichel, Brian Sliker, Leo Sveikauskas, Jack Triplett, and Cynthia Zoghi for helpful comments, suggestions, and encouragement at various stages of this line of work. Any errors are entirely my own. 
accounting studies by Stephen Oliner and Daniel Sichel (2000) and by Dale Jorgenson and Kevin Stiroh (2001) concluded that computer quality was, perhaps, the most important source of U.S. productivity growth in the late 1990s. However, European national accountants found reasons to be skeptical. For example, Peter Hill (2000) pointed out that quality adjustments made from vintage accounts of prices reflected only the positive aspects of quality change while neglecting some negative effects.

This paper uses diagrams as well as formal definitions to shed some light on the implications of the rigid assumptions about vintage aggregation made in our standard total factor productivity work. The approach appeals to two different models of how technology and capital formation can explain growth in labor productivity, both proposed by Robert Solow $(1957,1960)$. The first model assumed that technology was "disembodied" in that it raised productivity independently of the level of investment. Vintage investments were summarized in a "capital stock" measure that was used to separate the contributions of capital and of "residual" technology change to labor productivity growth. This first model is the basis for modern neoclassical total factor productivity exercises. In the second Solow model, technology was "embodied" in capital, and the contribution of each "vintage" of capital to labor productivity could be different. This second model was equally rooted in neoclassical concepts, but it did not make the rigid assumptions needed to build a capital stock. Instead, Solow described the dynamic allocation of labor among capital of different vintages.

After a brief review of relevant material on models of production, capital measurement, and quality adjustment (section 4.2), this paper develops a "model of production with machines" (section 4.3) in which the Solow vintage model is extended to individual machines. This machine model permits clearer definitions of key concepts such as deterioration and embodied and disembodied technical change. The machine model predicts that older vintages are preferentially discarded during a cyclical downturn. This realistic behavior is inconsistent with what is assumed in capital stock calculations. Section 4.4 examines the machine model in nominal terms.

Section 4.5 considers the idea of real capital input. The machine model is used to clarify previous discussions of what the marginal product of capital is - the added output obtained from a collection of machines by adding one machine (not a machine hour) and without adding any labor. Section 4.6 discusses how quality adjustments to capital inputs could be overstated.

\subsection{Some Background on Models of Growth, Capital Stocks, and Quality Change}

\subsubsection{The Solow Residual Model}

Solow's (1957) residual model constructed an aggregate capital stock, $K$, and used it in a production function, $f$, of the form $Y=f(L, K, t)$, where 
$Y$ is a real value added output measure, $L$ is labor hours, $K$ is aggregate capital stock, and $t$ is the time of observation, to parse out the contributions to labor productivity growth of capital and of shifts in the production function. ${ }^{1}$ Solow showed that

$$
(y-l)=s_{K}(k-l)+a,
$$

where $y, l$, and $k$ represent the growth rates of output, labor, and capital stock, respectively, and where $s_{K}$ is the share of capital or property income, $\Psi$, in the value of output. Property income is calculated using output prices, $p$, and wages, $w$, as the residual of labor compensation in nominal value added output: $\Psi=p Y-w L$. The "Solow residual," $a$, is a measure of disembodied technical change in that it is presumed to contribute independently of the level of investment in capital. The growth rate of $a$ is typically determined as the residual of output growth not accounted for by growth in capital and labor inputs. Hulten (2001) reviewed many studies which have measured the residual, most commonly known as total factor productivity growth. The Bureau of Labor Statistics (BLS; 2001) produces measures of $a$, which it calls multifactor productivity, using the same general methods.

Time series estimates of labor productivity and of $a$ are procyclical. This has been a troubling problem for neoclassical models because $a$ is designed to measure technological progress that should not be highly sensitive to the cycle. This issue was explored by Catherine Morrison and Ernst Berndt (1981). Many ideas, such as labor hoarding and disequilibrium, have been put forth in an effort to reconcile apparent short-run increasing marginal returns to labor with the neoclassical prediction of diminishing returns. Section 4.5 will show how the cyclical nature of the residual is partly a consequence of the rigidity with which capital is measured.

\subsubsection{The Solow Vintage Model}

"The controversies still rage[d]" when Harcourt $(1969,369)$ wrote his account of a bitter debate in the literature over whether capital measurement is useful. An understanding of the issues had gradually emerged in the context of Leontief's (1947) aggregation theorem. To build a stock, capital had to be like jelly - the ratios of marginal products of different investments could not vary as functions of output or other inputs in the production function. Empirically, the Leontief conditions are rarely satisfied. For example, newer electric power plants are used continuously while older plants are reserved to meet peak demand. Another example is that one fast computer is not a perfect substitute for two slow machines for which the total cost is the same because the latter are designed in most cases to work with two people.

1. The derivation involves differentiating the production function with respect to time, assuming constant returns to scale, that input prices are given, and that inputs are paid the values of their marginal products. 
In response to this type of problem, Solow (1960) had proposed a vintage capital model. In this model, each vintage, $v$, of capital has its own production function, $f_{t, v}$, where $v$ is the time at which the capital was initially marketed or sold. The function describes how much output could be made with any given amount of surviving capital, $K_{t, v}$, and labor, $L_{t, v}$, in any period subsequent to the year of an initial investment, $I_{v}$ :

$$
Y_{t, v}=f_{t, v}\left(K_{t, v}, L_{t, v}\right)
$$

This allowed for technical progress to be embodied in capital goods. To enforce the idea that vintage production functions are separate, Solow imposed the ground rule that firms must apply labor to specific vintages with no joint effects. Thus, the observed totals for labor hours and output are the sums of vintage specific contributions:

$$
L_{t}=\sum_{v} L_{t, v} \text { and } Y_{t}=\sum_{v} Y_{t, v}
$$

This structure accommodates heterogeneity among the production processes used by capital assets of different vintages. In some year, the capital measure required for the Solow residual model might count two slower computers as the same amount of capital as the one fast one. These relative valuations, however, might change over time, and so an aggregate measure of capital counting the two types of machines according to a fixed relationship could be inconsistent, that is, ambiguous.

\subsubsection{The Hall Equation}

A vintage aggregate of investments, or capital stock, is commonly used to calculate the Solow residual. The theoretical conditions under which this aggregate is consistent were thoroughly reviewed by Franklin Fisher (1965). A capital services aggregate,

$$
J_{t}=\int_{v} z_{t, v} I_{v} d v
$$

effectively assumes vintage investments are featureless perfect substitutes, implying that capital is like "jelly," denoted $J$. Fisher showed that in order for $J$ to be consistent, the efficiency function, $z$, must adjust the quantity measure for all differences in marginal product while remaining independent of output prices and wages. Seemingly, $z$ had to be a predetermined function of time. Hall (1968) argued, however, that there is latitude in defining jelly. He observed that:

The basic theorem on capital aggregates makes no restriction on the behavior of the function $\mathrm{z}(\mathrm{v})$ over calendar time. From one year to the next, the pattern of efficiency as a function of vintage may change arbitrarily. ... This formulation is so general as to be almost vacuous. (36)

In proposing that the recipe for jelly could be changed from year to year, Hall recognized that this generalization was so vast as to obscure the 
capital-related phenomena addressed in previous literature. To reach an interpretation, he proposed a structural form for $z$ involving a decomposition into three factors that he could loosely associate with important phenomena: functions of time $\left(d_{t}\right.$, disembodied technical change), of age ( $\phi_{t-v}$, deterioration), and of vintage ( $b_{v}$, embodied technical change):

$$
J_{t}=\int_{v} z_{t, v} I_{v} d v=d_{t} \int_{v} \phi_{t-v} b_{v} I_{v} d v
$$

Hall then pointed out that functions $d_{t}, \phi_{t-v}$, and $b_{v}$ reflect only two independent influences, time and vintage, and so the specification can be written in terms of two functions, eliminating the third by including its influence in respecified versions of the other two. This pulled the two Solow models together under a particular specification, which I will refer to as Hall's equation (5).

\subsubsection{Quality Adjustment to Capital Measures}

New improved models of high-tech equipment that embody improvements are frequently introduced and marketed alongside older models. Quality adjustment involves comparing prices of new improved goods to new unimproved goods. I will define each asset's model year, $m$, to be the year in which assets with a given design were first sold. Capital goods prices will be denoted using three subscripts, $p_{t, v, m}^{K}$. In principle, a quality adjustment factor, $b$, can be defined by comparing the prices of brand new goods $(v=t)$ of the latest model $(m=t)$ to the prices of brand new goods of a previous period's model $(m=t-1)$. For example, matched models assume $b_{m} l$ $b_{m-1}=p_{t, t, t}^{K} / p_{t, t, t-1}^{K}$. Hedonic models estimate $b$ from wider sets of prices and characteristics. Statistical agencies then measure real capital by deflating measures of nominal capital expenditures, $E_{t}$, with a price index that tracks the price for a new good of constant quality:

$$
\frac{J_{t}}{J_{t-1}}=\frac{\left(E_{t} / p_{t, t, t-1}^{K}\right)}{\left(E_{t} / p_{t-1, t-1, t-1}^{K}\right)}
$$

This is equivalent to deflating with a quality-adjusted price index, that is, $J_{t} / J_{t-1}=\left(E_{t} b_{t} / p_{t, t, t}^{K}\right) /\left(E_{t} b_{t-1} / p_{t-1, t-1, t-1}^{K}\right)$. The quality-adjustment parameter factor, $b$, would seem to be the right factor to use in Hall's equation. However, this presumes relative prices of capital goods reflect their relative marginal products, a notion that will be critiqued in section 4.5.

\subsection{A Model of Production with Machines}

In this section, a model is developed describing production from individual machines, which could be almost any type of asset such as computers, trucks, or buildings. As in section 4.2, three subscripts are used to denote time, vintage, and model, where the model variable will be regarded as the time at which machines with specific physical characteristics were first 
sold in the market. This third subscript will be used in the formulation of definitions as well as in the description of available data on capital goods prices. Solow's vintage model (equation [2]) is modified to describe output as a function of labor associated with specific models, $m$, as well as specific vintages, that is, $Y_{t, v, m}=f_{t, v, m}\left(K_{t, v, m}, L_{t, v, m}\right)$. At any time the economywide stocks of each vintage and model, $K_{t, v, m}$, will be regarded as fixed by past investment decisions. A firm owning (and planning to keep) a machine, of type $t, v, m$, faces the following short-run production possibilities for generating output from labor:

$$
\frac{Y_{t, v, m}}{K_{t, v, m}}=g_{t, v, m}\left(\frac{L_{t, v, m}}{K_{t, v, m}}\right)
$$

The capital variable, $K_{t, v, m}$, involves aggregation across machines of type $t, v, m$. I will treat these machines as identical, but I will consider their discrete nature rather than treating $K_{t, v, m}$ as jelly. Let $\mathbf{K}_{t, v, m}$ refer to the set of all machines in existence at any time, $t$. Consider $\mathbf{K}_{t, v, m}$ to consist of discrete numbers, $n_{t, v, m}$ of identical machines. Assume that all machines in each vintage-model category are used identically at each point in time. Then total output from all machines of each vintage-model combination will be $n_{t, v, m}$ times the output of each machine. The machine production function, $f$, is then defined in terms of output per machine, by vintage and model:

$$
\left(\frac{Y_{t, v, m}}{n_{t, v, m}}\right)=f_{t, v, m}\left(\frac{L_{t, v, m}}{n_{t, v, m}}\right) \quad \forall v, m \subset \mathbf{K}_{t, v, m}
$$

Assume that the output coming from each machine is a smooth function, $f$, of labor and is characterized by diminishing marginal returns to labor. Figure 4.1 depicts such a machine production function, $f$. If the firm chooses to operate at point $A$, the average product of labor (labor productivity) will be the slope of ray $O A$ and the marginal product of labor will be the slope of the tangent to $f$ at $A$.

I next extend Solow's ground rule (equation [3]) so that labor is allocated to specific machines to produce output:

$$
L_{t}=\int_{v} \int_{m} L_{t, v, m} d m d v \text { and } Y_{t}=\int_{v} \int_{m} Y_{t, v, m} d m d v
$$

As in Solow's vintage model, assume that output and labor can be measured and that they are homogeneous. Also, cost minimization implies that the marginal product of labor applied to each machine will be the same (and will equal the wage rate relative to the price of output):

$$
\frac{\partial f_{t, v, m}}{\partial L_{t, v, m}}=\frac{w_{t}}{p_{t}} \quad \forall t, v, m
$$

In figure 4.2, three machine functions are depicted. Expression (10) implies they will be operated at points where tangents are parallel. It is also important to note that labor productivity differs by vintage (even though the 


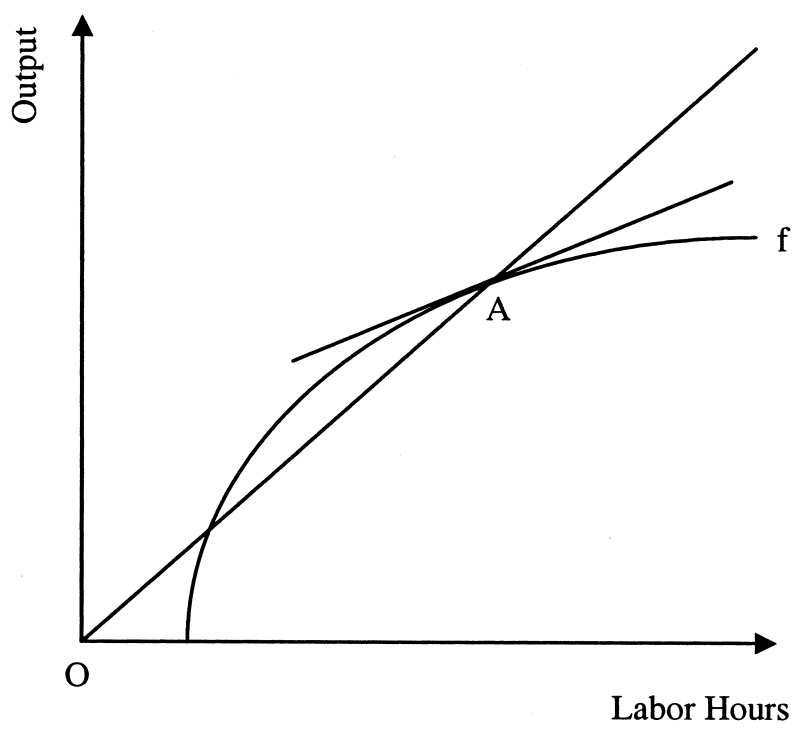

\section{Fig. 4.1 A machine production function}

Note: The firm can choose where to operate along $f$ and chooses $A$. The slope of ray $O A$ is the average product of labor (labor productivity). The slope of the tangent of $f$ at $A$ is the marginal product of labor.

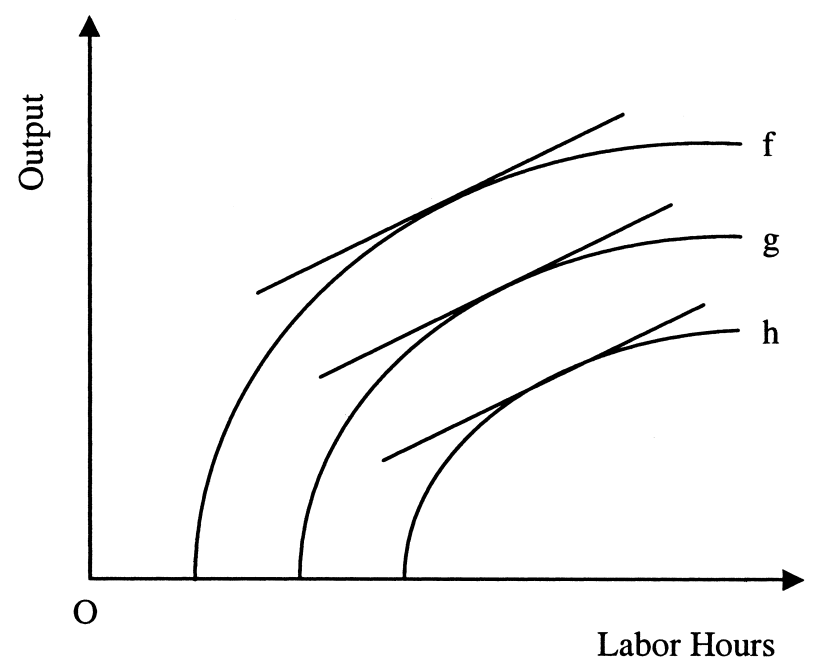

Fig. 4.2 A family of machine functions

Note: Several machines may operate simultaneously. Labor productivity may differ even though the marginal product is the same ( $f, g$, and $h$ are tangent to parallel lines). A machine's function may shift down with age due to deterioration or up with time due to disembodied technical change (or both). New machines tend to appear higher in the figure, meaning they allow higher labor productivity that is embodied technical change. 
marginal product of labor is the same). In this situation, if $w_{t} / p_{t}$ changed, labor would be reallocated in such a way that the marginal product of labor on all vintages would adjust proportionally to $w_{t} / p_{t}$, but note that the average product of labor could adjust differently on each vintage.

If this model were ever to be elaborated as thoroughly as Solow's residual model, issues such as the heterogeneity of labor and of output (composition or quality effects) and the relationships among different types of capital might be addressed. However, in order to facilitate exposition, this paper will describe a situation where one type of output is made with one type of labor using progressively advancing versions of one type of machine.

\subsubsection{Relationships among Functions}

Zvi Griliches (1963) made one of the most thorough efforts in the literature to define the key concepts of capital measurement, such as replacement, depreciation, deterioration, obsolescence, and capital services. This paper will provide similar definitions that refer to the machine model. In order to facilitate compact mathematical definitions and analysis of phenomena associated with capital, it is assumed that machine production functions, $f_{t, v, m}$ and related variables are continuous functions of time, vintage, and model.

As machines age, their physical characteristics change due to wear and tear. The rate of deterioration of output, $\chi_{t, v, m}^{f}$, (the output decay rate) is defined as the rate at which the output produced by a given amount of labor with a given model varies by vintage:

$$
\chi_{t, v, m}^{f}=\frac{\partial \ln f_{t, v, m}}{\partial v}=\frac{-\partial \ln f_{t, v, m}}{\partial(t-v)}
$$

As indicated, this will be the negative of the rate at which output varies by age alone for a given model. Note that the deterioration rate can vary with time, vintage, or model. Newer models embody features that permit them to make more output with the same amount of labor. The rate at which functions differ due to embodied technical change, $B_{t, v, m}^{f}$, is defined in terms of models, or equivalently, model age:

$$
B_{t, v, m}^{f}=\frac{\partial \ln f_{t, v, m}}{\partial m}=\frac{-\partial \ln f_{t, v, m}}{\partial(t-m)}
$$

These are the only two types of shifts considered that are due solely to the machine's physical characteristics. However, as time passes, people may learn how to get more out of a given machine. Disembodied technical change, $D_{t, v, m}^{f}$, is the rate at which the function shifts over time for a specific model and age:

$$
D_{t, v, m}^{f}=\frac{\partial \ln f_{t, v, m}}{\partial t}
$$


There was an identification problem with Hall's (1968) specification in that deterioration $(\chi)$ and embodied $(B)$ and disembodied $(D)$ technical change were defined in terms of functions of time, vintage, and age $(t-v)$. These functions were defined, in turn, in terms of only two independent variables, $t$ and $v$. This is not the case here because a third independent variable, model, is introduced to control for the characteristics of new machines that differ even though they are sold as new in the same year. In principle one could use empirical observations to identify $\chi, B$, and $D$ separately. Identical brand new models made in different years could help identify disembodied technical change. Thus one could observe $f_{t+1, v+1, m} /$ $f_{t, v, m}$ to measure $D, f_{t, v+1, m} \mid f_{t, v, m}$ to measure $\chi$ and $f_{t, v, m+1} \mid f_{t, v, m}$ to measure $B$.

\subsection{The Nominal Earnings of Assets Described with the Machine Model}

This section will use the machine model to analyze the earnings of assets under dynamic conditions, such as how they are influenced by technology and cyclical fluctuations in demand. This material will be helpful in tackling the issues in measuring real capital in section 4.5.

\subsubsection{Extraction of Rents from Machines- \\ The Structure of the Shadows}

For each vintage and model, define the rent or property income, $\Psi_{t, v, m}$, generated per machine as the difference between revenues and variable costs associated with the machine:

$$
\frac{\Psi_{t, v, m}}{n_{t, v, m}}=\frac{p_{t} Y_{t, v, m}}{n_{t, v, m}}-\frac{w_{t} L_{t, v, m}}{n_{t, v, m}}
$$

As Berndt and Fuss (1986) assumed, in the short run, firms can be expected to behave as if capital costs are fixed and sunk, and so they will go about the business of maximizing the rate at which they accrue property income, $\Psi_{t, v, m}$. The ex post rents generated by the aggregate capital stock emerge as the shadow price of the capital stock. The machine model supports an explanation of how output prices and wages influence decisions on operating individual machines. This begins by assuming that, in the short run, each firm has a fixed collection of assets and is too small to influence wages and output prices. Assume that each firm will extract as much rent as possible from each machine it owns. With a given price, a given wage, and a given set of machines in place, the decision as to how much to run each machine can be represented in terms of values rather than in terms of input and output units. The following describes how much revenue can be earned from one machine as a function of expenditure on labor costs:

$$
\frac{p_{t} Y_{t, v, m}}{n_{t, v, m}}=f_{t, v, m}^{\prime}\left(\frac{w_{t} L_{t, v, m}}{n_{t, v, m}}\right),
$$




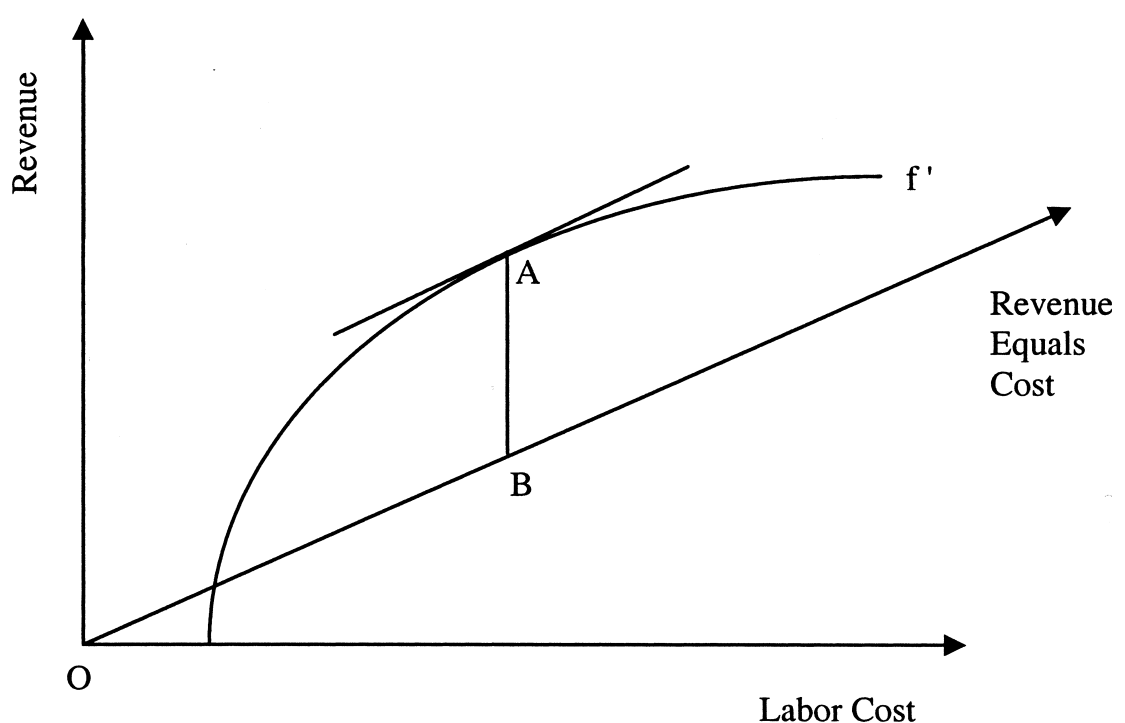

Fig. 4.3 Revenue function

Note: The machine owner is a price taker for both wages and product price (these are exogenous). For a given wage and price, the machine function, $f$, can be projected into a revenuecost plane. The revenue function, $f^{\prime}$, will look exactly like $f$ if the revenue and cost axes are suitably normalized ( $w=1, p=1)$. Ray $O B$ delineates where revenue equals labor cost. The owner will choose operating at point $A$, where the tangent to $f^{\prime}$ is parallel to $O B$. Then segment $A B$ will measure rents (gross profits measured by revenue less variable cost).

where $f^{\prime}$ is a revenue function that is closely related to the corresponding machine production functions: $\partial f_{t, v, m}^{\prime} / \partial L_{t, v, m}=w_{t} \partial f_{t, v, m} / \partial L_{t, v, m} \forall t, v$, and $m$.

Given the assumed price-taking behavior at any time, $t$, one can relabel the axes of figure 4.1 as "revenues" and "labor costs" and construct the scale so that $w_{t}=1$ and $p_{t}=1$. Then the revenue function, $f^{\prime}$ will be in the same location as $f$, as depicted in figure 4.3. Ray $O B$ has been added through points in the first quadrant for which revenues equal labor costs. A machine earns positive rents when operated at any point above ray $O B$. Rents will be at a maximum when expression (14) is satisfied, so the firm will operate at point $A$. The tangent to $f^{\prime}$ at $A$ is parallel to $O B$. Line segment $A B$ is a measure of the rents generated by the machine (revenue less cost).

\subsubsection{Visualizing Changes in Output Prices or Wages}

Fixed output prices and wages are built in to figure 4.3. The revenue function would move when prices or wages changed, while the ray, $O B$, would remain fixed. If the price of output declined, all points on the function would shift proportionally downward. Similarly, if wages rose, the function would shift rightward and would be stretched to the right. With a 


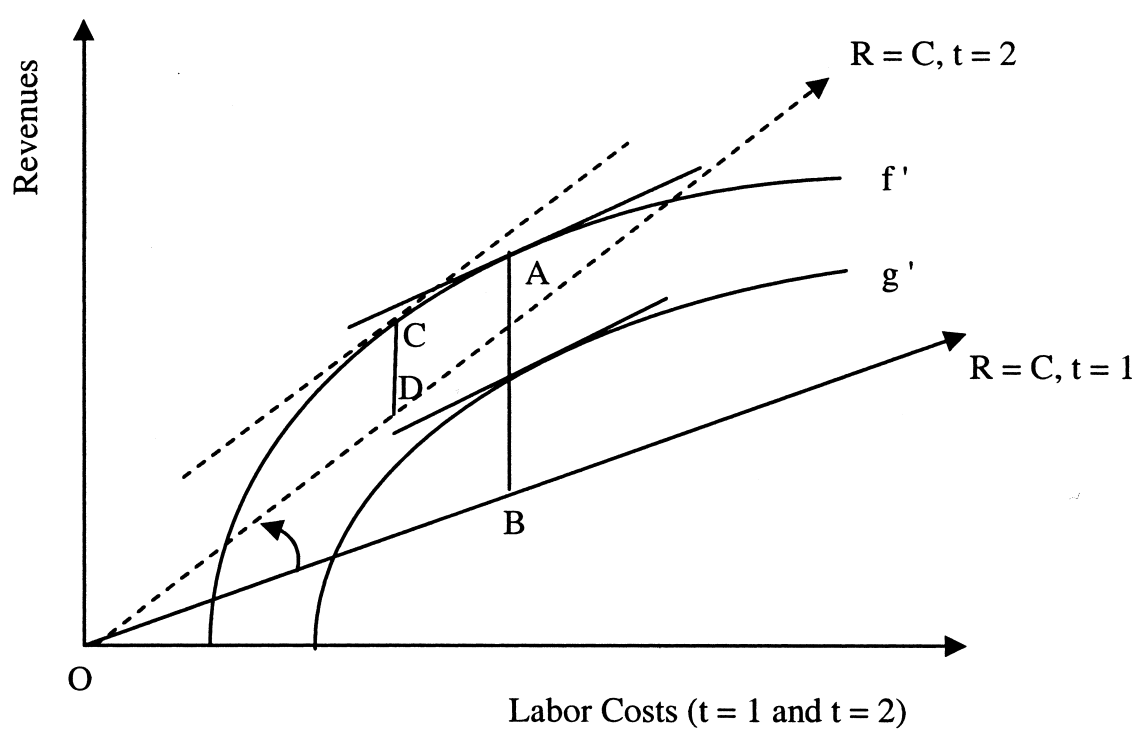

Fig. 4.4 The dynamics of a wage increase

Note: If wages rise relative to prices, the revenue $=\operatorname{cost}$ ray, $O B$, would remain fixed and the functions, $f^{\prime}$ and $f^{\prime}, g^{\prime}$, would shift and elongate rightward. However, it is possible to renormalize the axes in the plane as wages rise so that the functions stay put. The revenue $=$ cost ray would then appear to rotate upward, to the position of ray $O D$. The rents from $f^{\prime}$ will be driven down from the length of segment $A B$ to that of segment $C D$. Note that labor productivity rises slightly (the slope of $O C$ is greater than that of $O A$ ). Machine $g^{\prime}$ meets a different fate: rents become negative after the wage increase, and so it is shut off abruptly to avoid an operating loss.

little imagination, figure 4.3 can be used for a different visualization of the consequences of changes in these variables. Rather than redrawing all of the curves, one can simply adjust the scales by renormalizing wages and prices. Then the revenue function will stay in its original place, and $O B$ will appear to rotate counterclockwise (up) through the first quadrant, perhaps to position, $O D$, as depicted in figure 4.4. A wage increase would reduce the rents earned from $f^{\prime}$ from the length of segment $A B$ to that of $C D$. (An output price decrease would involve a change in the scale of the vertical axes, ruining the correspondence of vertical segment lengths to rents, so we will focus on the wage increase.) This illustrates how a wage increase drives down rents and creates pressure to economize on labor. Note that $C D$ is to the left of $A B$. Faced with a wage increase, the firm will reduce the amount of labor and output slightly, raising average labor productivity, consistent with what Cooper and Haltiwanger (1993) have observed happening to plants as they aged. In the long run, technological improvements generally lead to investments in improved capital goods that, in turn, bid for scarce labor, driving a persistent upward rotation in the ray representing revenue 
equals cost. The effect of obsolescence is just the rent lost due to the persistent rise in wages relative to the price of output. This rise (or rotation in ray $O B$ ) is not necessarily a constant - a cyclical downturn in the economy can accelerate the upward rotation of the ray, while a surge in demand can temporarily reverse the process, causing a downward rotation of ray $O B$ and an increase in rents. A key point is that the rotation of $O B$ reflects both temporal and cyclical influences. The two exogenous influences tend to get swept together in the standard approach to capital measurement. The temporal influence creates obsolescence, while the cyclical influence is what underlies the Berndt and Fuss (1986) "temporary equilibria."

\subsubsection{Negative Rents, If Permanent, Will Induce Asset Retirement}

Negative rents would occur if wages rose enough so that a revenue function fell entirely below the revenue or cost ray, as is the case with $g^{\prime}$ and ray $O D$ in figure 4.4. Negative rents can occur if the revenue function has a fixed labor requirement. No output (revenue) is produced unless this requirement is met, but once it is met, the function rises rapidly. If $O D$ is high enough, and if diminishing marginal returns set in soon enough, revenues may never cover costs. Any attempt to operate the machine will result in a loss. In this situation, we assume that the machine is shut down. Unlike a capital stock, the machine model can be consistent with an abrupt shutdown of a machine or plant - as $O B$ rises (and before it reaches $O D$ ), rents would transition from positive to negative, causing all labor suddenly to be withdrawn from the asset. This type of model could potentially be used with microdata to investigate plant closing behavior, but this paper will focus on measuring capital.

In order to predict abrupt retirements, the machine model must be specified with a fixed labor requirement as in my figures. ${ }^{2}$ This cannot happen with the Cobb-Douglas specification ${ }^{3}$ of the vintage production function that Solow (1960) used in an empirical exercise. As depicted in figure 4.5, Solow's functions would start at the origin and move out into the first quadrant, with newer vintages above older. The slope of each curve would gradually decline, reflecting diminishing marginal returns to labor. But there would be diminishing average returns to labor throughout each curve. If the ray $O B$ gradually rotated upward squeezing rents, the firm would continue to operate the machine using less and less labor until labor reached zero. Falling rents would not lead to abrupt shutdowns, and, instead, old machines would just gradually fade away.

It is interesting that on any function, $f$, that has a region where labor productivity is rising, labor productivity will reach a maximum at the point at

2. This can happen with any specification with a region where average returns to labor (labor productivity) are rising.

3. Output per unit of capital, with the Solow's vintage Cobb-Douglas function, is given by $\left(Y_{t, v} / K_{t, v}\right)=B e^{\lambda v}\left(L_{t, v} / K_{t, v}\right)^{\alpha}$. 


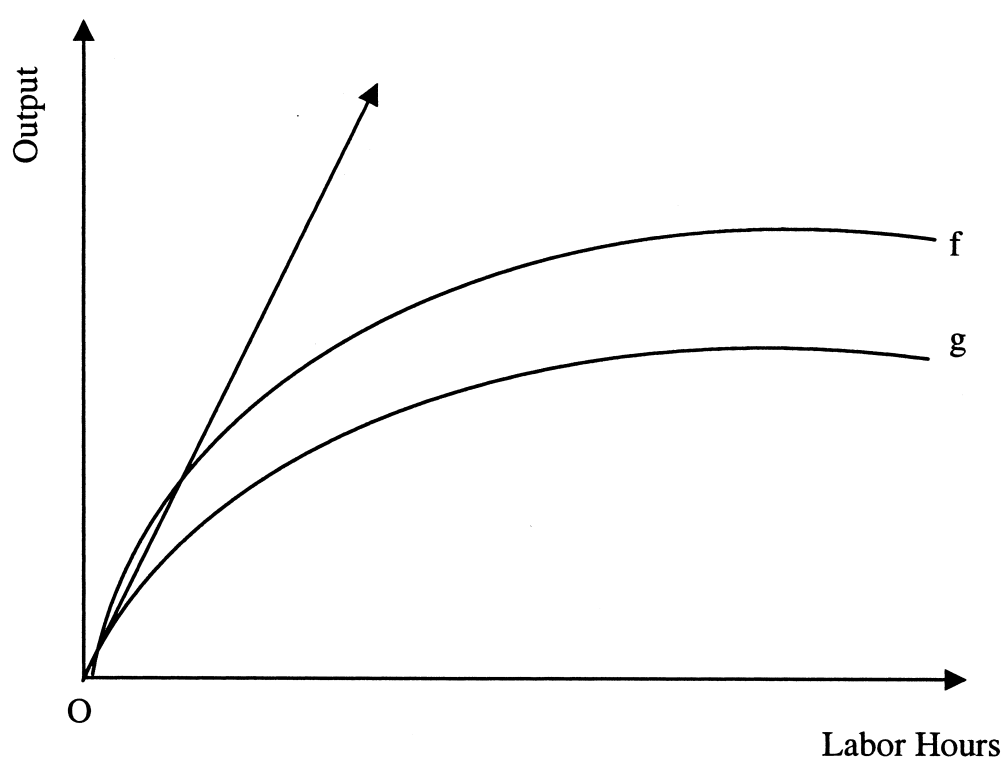

\section{Fig. 4.5 Cobb-Douglas specification}

Note: Solow mentioned one possible specification for his vintage production function, and here it is graphed for two machines. Because there is no part of the domain where there are increasing average returns to labor, rents will only approach zero as wages become very high. Negative rents are impossible, and there is not an abrupt transition from operating with a lot of labor to being shut down. Old machines do not die, they just gradually fade away.

which the curve is tangent to a ray from the origin. As a consequence of diminishing marginal returns, a machine will never operate to the left of this point. It follows that the labor productivity associated with a machine is at its maximum when the machine is marginal. Machines will operate to the right of this point.

\subsection{Measuring Real Capital}

Given the machine model, we now consider what measurement units and weights would be suitable for the aggregation of real capital inputs.

\subsubsection{Measurement Units and the Aggregation of Machines}

The machine model can be used to devise an aggregate capital measure that reflects many of the factors affecting capital vintages. This perspective will help to identify how these factors are being treated in recent studies of capital and productivity. The model includes a unit, the number of machines, $n_{t, v, m}$, that can be used to add up identical assets. This is a less constrained starting point for vintage aggregation than the usual real value of investment. However, each category of machine is different. Expression (4) 
indicates that machine counts need to be weighted by marginal products in order to satisfy the Leontief aggregation conditions. The intuition is that investments must be adjusted for how much work they do.

In productivity measurement, the Bureau of Labor Statistics (BLS) adjusts employment by average hours. Many authors have considered an analogous treatment of capital, that is, adjusting the number of machines, $n_{t, v, m}$, for the intensity of their use. The idea is to adjust for the cyclical changes in marginal product. Jorgenson and Griliches (1967) originally made capacity utilization adjustments, but they later decided to avoid measuring capital in terms of other variables in the production function, like labor hours or energy use. These adjustments seemed to undermine the notion of an independent capital measure. As Berndt and Fuss (1986) pointed out, weighting capital with its shadow price is tantamount to adjusting for capacity utilization, and so a quantity-side adjustment in the Jorgenson and Griliches framework would account for capacity utilization twice. Present day neoclassical capital measurement studies, such as Jorgenson and Stiroh (2001) and the BLS (2001) measures, do not make quantity-side capacity adjustments.

Nevertheless, let us work through the idea of making a quantity-side adjustment for capacity utilization instead of a rental price-side adjustment. We would need to adjust the quantities for variations in marginal product. In general machine hours, $h_{t, v, m}^{K}$, will not correspond to the marginal product of capital. Workers lose utility by giving up leisure time to work - and so they are (usually) compensated by the hour. But idle capital has no utility, and an asset's owner is (usually) not compensated by how many hours per day it is used. Once an asset is acquired, it is used for as many hours per day as necessary to maximize the difference between revenues and labor costs. So in the temporary equilibrium described by Berndt and Fuss (1986), the marginal value of running a machine one more hour per day will be zero, $\partial \Psi_{t, v, m} / \partial h_{t, v, m}^{K}=0$. That is, one machine hour is not equivalent to another, and the contribution of the last hour is marginal. Therefore the total hours of each type of machine is not necessarily the appropriate weight for use in the aggregation of machines.

\subsubsection{The Marginal Product and Rental Price of a Machine}

While Fisher (1965) showed that vintages needed to be aggregated in terms of marginal product (expression [4]), the literature lacks a careful discussion of what the marginal product of capital is. Present measurement conventions regard "a spade to be a spade" (the "Gertrude Stein dictum," as Harcourt [1969, 372] put it), so a brand new machine of a given model is assumed to represent the same amount of capital (to have the same marginal product) in each time period. Thus, the quantity unit for capital is tied exclusively to the inherent characteristics of the machine.

The machine model leads to a very different conclusion. When a ma- 
chine is added to the economy while total labor is held constant, the output of the new machine will be gained, but some output from other machines will be lost because labor must be redeployed to the new machine and away from other machines. ${ }^{4}$ Because labor is always redeployed at labor's marginal product, the new machine will boost output by the difference of the average product of labor on this machine, and the marginal product of labor (which will be the same on the new machine as on all other machines). Hence the marginal product of machines, $z_{t, v, m}=\partial Y_{t} / \partial n_{t, v, m}$, is

$$
z_{t, v, m}=\frac{Y_{t, v, m}}{n_{t, v, m}}-\frac{L_{t, v, m}}{n_{t, v, m}} \frac{\partial Y_{t, v, m}}{\partial L_{t, v, m}}=\left(\frac{Y_{t, v, m}}{L_{t, v, m}}-\frac{\partial Y_{t, v, m}}{\partial L_{t, v, m}}\right) \frac{L_{t, v, m}}{n_{t, v, m}} .
$$

The marginal product of the machine is determined by its own machine production function and by the marginal product of labor, which in turn is determined by the ratio of exogenous functions of time, $w_{t} / p_{t}$. Marginal product closely corresponds to rent. Rent per machine, or the machine rental price, $c_{t, v, m}$, is just the price of output times the machine's marginal product:

$$
c_{t, v, m}=\frac{\Psi_{t, v, m}}{n_{t, v, m}}=p_{t} z_{t, v, m}
$$

Note that, $c_{t, v, m}$ reflects the marginal product of capital in that differences in marginal products between machines, $z$, will show up as differences in the rental prices, $c$.

It is possible to picture how a machine's marginal product changes by projecting figure 4.4 back into the output-labor-hours plane of figure 4.1. Figure 4.6 depicts the rays $O B$ and $O D$ representing the two given wageprice ratios, projected into output-labor space. Marginal products are proportional to the vertical distances between each operating point and the relevant ray. As the wage-price ratio changes, the vertical distances associated with different vintages will clearly change. If figure 4.6 depicted several functions like figure 4.2 , it would be clear that the marginal products of machines are affected disproportionately by variations in the exogenous price of output and wage rate. In particular, rents and the marginal prod-

4. An example may help. Suppose there are fifty identical machines in the economy, each machine using ten workers to make 100 units of output (500 workers and 5,000 units of output in all). If one more machine is added to the economy and ten more workers, 100 more units of output will be produced. But to compute the marginal product of capital, total labor must be held fixed, so ten of the fifty-one machines now must be operated with only nine workers. If these ten machines now produce only ninety-four units of output each, the net gain from adding the fifty-first machine to the economy would be only forty units $[100-10 \cdot(100-94)]$. This marginal product will depend on how scarce labor is. Had we started instead by operating the fifty machines with only seven laborers making eighty units of output each, the introduction of the fifty-first machine would require seven machines to be operated with six workers each, the seven machines producing perhaps only seventy units each. Then the marginal product of capital would be only ten units $[80-7 \cdot(80-70)]$. The usefulness of another machine is lower when labor is a relatively scarce resource. 


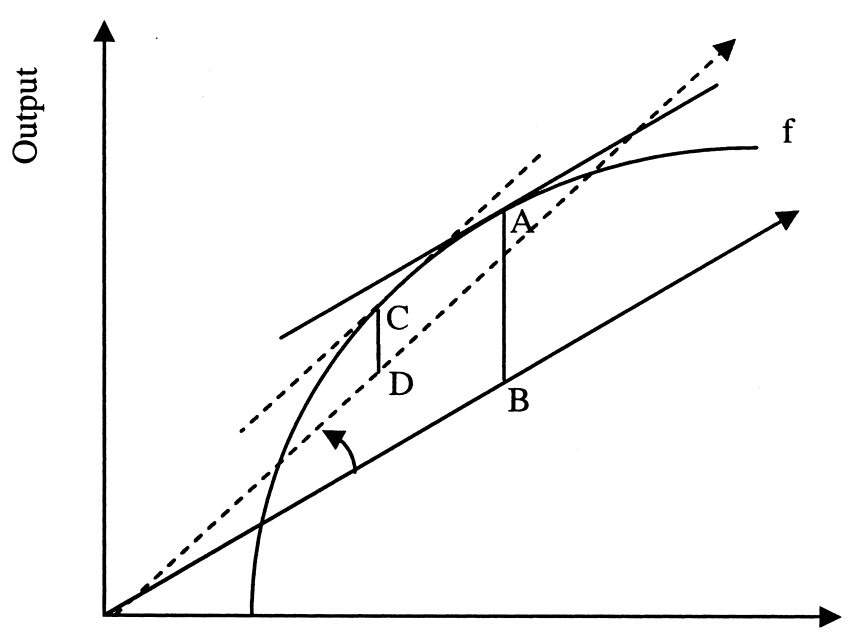

$\mathrm{O}$

Labor Hours

Fig. 4.6 The marginal product of a machine

Note: Rays $O B$ and $O D$ in figure 4.4 can be projected back into output-labor-hours plane of figure 4.1. Segments $A B$ and $C D$ then represent the marginal product of the machine before and after the wage increase. Even though the machine is exactly the same, the marginal product of the machine is driven down by an increase in wages because the opportunity cost of labor (the output the worker could make with some other machine) has risen. In the long run, technical change and investments in efficient assets drive a steady upward rotation of the ray.

ucts of older assets are affected proportionally more by cyclical effects and by obsolescence than are the rents and marginal products of newer more productive assets. The Leontief aggregation conditions require ratios of marginal products among machines to be independent of exogenous variables. Capital stock measures impose this, at odds with how assets with differences in productivity will behave.

\subsubsection{The Rigid Homogeneity Assumption Underlying Capital Stock Measures}

One possible arrangement of machine functions is of special significance. A group of machines, $\mathbf{G}_{t, v, m}$, is defined to be homogeneous if, for any two functions, $f_{i, j, k}$ and $f_{t, v, m} \subset \mathbf{G}_{t, v, m}$ there exists an $\alpha_{i, j, k}$ such that:

$$
f_{i, j, k}\left(\alpha_{i, j, k} L\right)=\alpha_{i, j, k} f_{t, v, m}(L) \quad \forall L .
$$

Fisher (1965) and Hall (1968) used different proofs to show that vintages must be homogeneous in order for the vintage aggregate, $J$, to exist. Figure 4.7 illustrates the similarity of machine functions for a homogeneous group of machines. For any given $p_{t} / w_{t}$ ratio, all machines will operate with the same proportions of output and labor, that is, the same labor productivity. One function is never strictly above another like in figure 4.2 , that is, 


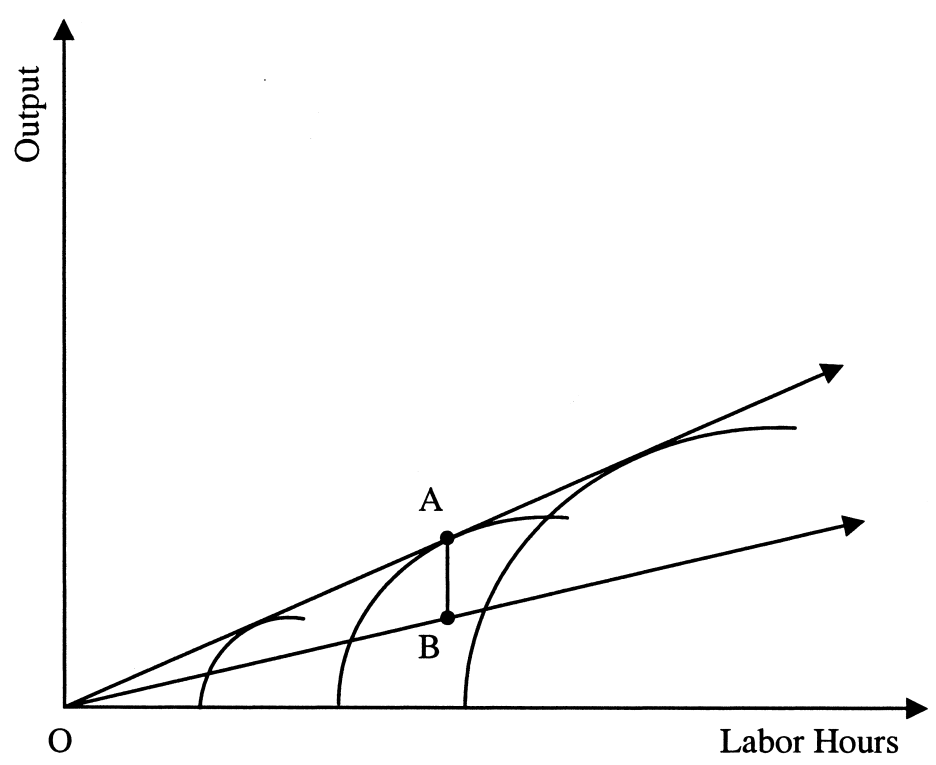

Fig. 4.7 A family of homogeneous machine functions

Note: The Leontief aggregation conditions fail unless the relative marginal products of machines are unaffected by the rotation of ray $O B$. Machines with higher potential labor productivity than others (like in figure 4.2) are ruled out of a homogeneous group. Machines can be bigger but not better. This is unsuitable for studying technologically improved equipment, but it is what economists assume in measuring capital stock.

one machine will never produce more output than another with the same labor. It is clear that two machines are not homogeneous if one of them embodies an improvement that enhances labor productivity. Nor can an older machine, whose machine production function has deteriorated, be part of the same homogeneous class as a new machine.

Within a homogeneous group, machines can produce different amounts of output with proportionally different amounts of labor input. Call the value of $\alpha_{i, j, k}$ that satisfies expression (18) the size of machine $i, j, k$ compared to machine $t, v, m$. A new machine can be bigger but not better. Imposing a homogeneity assumption is implausible and inappropriate if one is interested in measuring high technology capital and characterizing the sources of growth. Yet such homogeneity is assumed in capital stock measurement.

What are the consequences of assuming homogeneity? The fixed ageefficiency schedule is at odds with the fact that relative marginal products will vary by vintage. The fixed schedule imposes homogeneity, as defined by equation (18) on the vintage machine production functions. All vintages are assumed to be affected proportionally by a demand shock. In effect, vintage machines are assumed to differ only in size. To the extent that as- 
sets actually differ in labor productivity, as in figure 4.2, any exogenous shock should actually affect the marginal products of the oldest and least efficient vintages proportionally more than those of the newer ones. Because of the built-in homogeneity assumption, capital stocks can lead to puzzling results when used in short-run models, such as those reported by Brynjolfsson and Hitt (2003).

An age-efficiency function could be constructed to correct for any steady and persistent temporal influence such as obsolescence, as Wykoff (2003) has suggested. In this case, the age-efficiency function is adjusted for the effects on marginal product of obsolescence (the upward rotation of ray $O A$, as in figure 4.6) as well as the effects of deterioration in the function $f$. However it is clear that a time-invariant-age-efficiency function will be unable to correct for cyclical influences. The idea of a capacity utilization adjustment is to correct for this problem. However, a capacity utilization ratio for the capital stock will not accurately model the myriad vintagespecific adjustments to marginal products brought about by a cyclical change in demand. Ideally, a separate capacity adjustment would be calculated for each vintage. The vintage aggregate capital service measure would then be the sum across vintages of investments adjusted for capacity effects, as well as for deterioration and obsolescence.

\subsection{Measuring Quality Change}

In the literature on quality adjustment of consumer goods, it is axiomatic that relative prices reflect relative utilities. In measuring inputs associated with durable capital goods, the usual assumption is that relative goods prices measure relative marginal products. My point of departure is that they do not.

Triplett (1989) recognized that rental prices rather than purchase prices should be used to compare marginal products. In neoclassical theory, the purchase price of an asset presumably equals the discounted value of its future rents. The ratio of purchase prices of two assets is therefore proportional to the ratio of their discounted streams of future rents and not necessarily to the ratio of marginal products. At first blush, it seems modest to assume the rental streams will be proportional to marginal products, ensuring that the purchase prices are in step with the rental prices. After all, such proportionality will occur if age-efficiency functions are geometric.

But if new machines embody technical change, that is, if the labor productivity associated with newer models is higher, and if the machine functions contain regions of increasing returns to labor (such as is the case if there is a fixed labor requirement for each machine), then obsolescence will push down rents of older models proportionately faster than rents of newer models. Because of this, the ratio of the price of a more productive model to that of a less productive model will overstate the ratio of marginal prod- 
ucts. As Hulten (1992) noted, the notion of capital quality is grounded in Hall's (1968) embodiment factor, which itself describes aggregation with marginal products.

\subsubsection{Obsolescence, the Functional Form of Marginal Product with Age, and Quality Change}

Observations of purchase prices, whether determined with hedonic or matched-model techniques, are required to measure quality. But information on the functional pattern by which obsolescence affects marginal products as models age also is required. For example, assume that models are impacted as they age by obsolescence, but not by deterioration. Oliner and Sichel (2000) contend that obsolescence dominates deterioration in contributing to a high-tech asset's demise. Further, assume that $w_{t} / p_{t}$ rotates upward at a steady rate without cyclical disturbances. Processes, such as quality improvements, are then presumed to occur at fixed rates so that the quality of a new model, in any year $t$, relative to one introduced one year earlier will be $B_{t}=z_{t, t, t} / z_{t, t, t-1}$. Let $\gamma_{\tau}$ be the age $(\tau) /$ efficiency function, i.e. $\gamma_{\tau}=z_{t, t, t-\tau} / z_{t, t, t}$. Under the assumptions, $B_{t}=1 / \gamma_{1}$. From the neoclassical axiom that the price of an asset equals the discounted future rents, one can determine the price of a new model relative to last year's model:

$$
\frac{p_{t, t, t}^{K}}{p_{t, t, t-1}^{K}}=\frac{\int_{u=0}^{\infty} p_{t+u} \gamma_{u} e^{-r u} d u}{\int_{u=0}^{\infty} p_{t+u} \gamma_{u+1} e^{-r u} d u}=\frac{B_{t} \int_{u=0}^{\infty} p_{t+u} \gamma_{u} e^{-r u} d u}{\int_{u=0}^{\infty} p_{t+u}\left(\gamma_{u+1} / \gamma_{1}\right) e^{-r u} d u}
$$

If quality raises the labor productivity of newer models, (which it must do if there is a technological improvement as distinct from an increase in size), rents, $p \gamma$, will be forced down by obsolescence proportionally faster with age, i.e. $d^{2} \ln \gamma_{\tau} / d \tau^{2}>0$, and the machine will eventually be retired, that is, $\gamma_{\tau}=0$ for $\tau>L$. Under these conditions the ratio of integrals on the righthand side of expression (19) will be greater than one. The ratio of model prices will exceed relative quality.

The bias in the existing durable goods quality adjustments is likely to be substantial. Figure 4.8 plots the marginal products of hypothetical goods. For example, computers could be depicted by straight-line-age-efficiency functions with short lives. The age-efficiency functions decline because of the temporal effects of a steady increase in $w_{t} / p_{t}$. Newer models embody technical improvements. The relative marginal product of a newer model to that of an older one at any time would be proportional to the ratio of heights of the lines in left-hand-side portion of figure 4.8. The relative asset prices will be proportional to a ratio involving areas. Thus, the area under each line, from a given time through the rest of the life of the asset, will represent the asset's (nondiscounted) future rents. If the discount rate is zero and the effects of obsolescence are straight-line, as in figure 4.8, qual- 

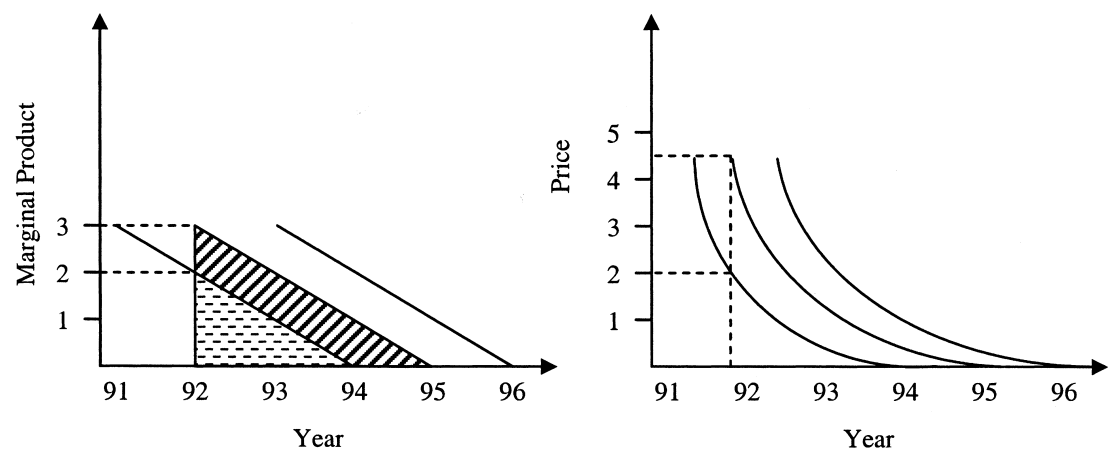

Fig. 4.8 Tracing vintage marginal products and prices

Note: Obsolescence causes the marginal products of machines of any model to fall over time. For example, suppose the marginal product of a new model in 1992 is three units of output and that of a new 1991 model (in 1992) is two units. Assuming interest rates are negligible, the price of each asset will reflect the remaining area under its marginal product curve. This is the light shaded area for the 1991 model and the total of the light and dark areas for the 1992 model. The ratio of prices (in units of output) will tend to exceed the ratio of marginal products. In the example, the older model has $2 / 3$ the marginal product but only $4 / 9$ of the price of the newer one. If the marginal products decline along parallel straight lines and interest is negligible, the price ratio will be the product of the effects of marginal product $(2 / 3)$ and of future obsolescence (2/3). Thus, for small price differentials, quality will be overstated by a factor of about two.

ity change would be overstated by a factor of about two. For an agemarginal-product relationship that declined slowly at first and then faster in absolute level with age, as the BLS assumes, the factor would be even higher. Quality-change bias could occur in successive years for the reasons outlined here. If so, the bias will compound over time in a chained-index number.

A geometric age-efficiency specification appears to escape the problem, that is, $\gamma_{u+1} / \gamma_{1}=\gamma_{u}$ for all $u$, reducing the right-hand side of equation (19) to $B_{t}$. The age-efficiency profiles of all models will fade away proportionately, and, therefore, corresponding goods prices will take on the same proportions. Before taking any comfort in this, note that a geometric ageefficiency function cannot describe a situation where obsolescence erodes the marginal products of assets with older designs proportionately more than newer ones, as is likely to happen when the assets embody different technologies. Capital goods prices will be proportional to marginal products only if the geometric model really describes events at the microlevel, that is, only if the older and newer assets belong to a homogeneous family. This will not happen when, in reality, labor productivity in newer models is higher as a result of embodied quality improvements. In reality, obsolescence forces many older assets out of service. The idea that the older assets tend to be retired before newer ones is common sense. As retirement approaches, the level of an asset's marginal product approaches zero, declin- 
ing faster and faster in percentage terms. Hence $B_{t}$ must be greater than 1 . By assuming that $B_{t}=1$, consistent with a geometric model, the standard approach to quality adjustment disregards key evidence.

\subsection{Summary}

Capital stock measures are widely used in the economics literature. Capital stocks are constructed from data on vintage investment by means of strong aggregation assumptions. It is assumed that the capital services of vintage investments are predetermined and that they decay with age, independent of prevailing wages and output prices. These assumptions were identified as a potential limitation in the 1950s. Mechanisms have been developed to adjust capital stocks for the manifestations of these rigid assumptions. Capacity utilization adjustments to capital stocks account for cyclical variations in output, while quality adjustments are made to investments to correct for temporal improvements in the technology embodied in capital goods. Like capital stocks, however, these measurement adjustments involve strong assumptions. This has been recognized for decades in the case of capacity utilization. In the case of quality, the potential for bias may be underappreciated. I hope that this paper helps raise awareness of these issues and their importance to our understanding of economic growth.

\section{References}

Berndt, Ernst R., and Melvyn A. Fuss. 1986. Productivity measurement with adjustments for variations in capacity utilization and other forms of temporary equilibrium. Journal of Econometrics 33 (1/2): 7-29.

Brynjolfsson, Erik, and Lorin M. Hitt. 2003. Computing productivity: Firm-level evidence. Review of Economics and Statistics 85 (4): 793-808.

Bureau of Labor Statistics. 2001. Multifactor productivity trends, 1999. U.S. Department of Labor News Release no. 01-125, May 3, 2001.

Cooper, Russell, and John Haltiwanger. 1993. The aggregate implications of machine replacement: Theory and evidence. American Economic Review 83:360-82.

Fisher, Franklin M. 1965. Embodied technical change and the existence of an aggregate capital stock. Review of Economic Studies 32:263-88.

Griliches, Zvi. 1963. Capital stock in investment functions: Some problems of concept and measurement. In Measurement in economics, ed. Carl Christ. Stanford, CA: Stanford University Press. Repr. in Technology, education and productivity, ed. Zvi Griliches, 123-43. New York: Basil Blackwell, 1988.

Hall, Robert E. 1968. Technical change and capital from the point of view of the dual. Review of Economic Studies 35 (January): 35-46.

Harcourt, G. C. 1969. Some Cambridge controversies in the theory of capital. Journal of Economic Literature 7 (2): 369-405.

Hill, Peter. 2000. Economic depreciation and the SNA. Paper presented at the 26th 
conference of the International Association for Research in Income and Wealth, Cracow, Poland.

Hulten, Charles R. 1992. Growth accounting when technical change is embodied in capital. American Economic Review 82 (4): 964-79.

2001. Total factor productivity: A short biography. In New developments in productivity analysis, ed. Charles R. Hulten, Edwin R. Dean, and Michael J. Harper, 1-47. Chicago: University of Chicago Press.

Jorgenson, Dale W., and Zvi Griliches. 1967. The explanation of productivity change. Review of Economic Studies 34 (3): 249-82.

Jorgenson, Dale W., and Kevin J. Stiroh. 2001. Raising the speed limit: U.S. economic growth in the information age. Brookings Papers on Economic Activity, Issue no. 1:125-235. Washington, DC: Brookings Institution.

Leontief, Wassily W. 1947. Introduction to a theory of the internal structure of functional relationships. Econometrica 15:361-73.

Morrison, Catherine J., and Ernst R. Berndt. 1981. Short-run labor productivity in a dynamic model. Journal of Econometrics 16:339-65.

Oliner, Stephen D., and Daniel E. Sichel. 2000. The resurgence of growth in the late 1990s: Is information technology the story? Journal of Economic Perspectives 14 (4): 3-22.

Solow, Robert M. 1957. Technical change and the aggregate production function. Review of Economics and Statistics 39 (3): 312-20.

- 1960. Investment and technical progress. In Mathematical methods in the social sciences, ed. K. Arrow, S. Karlin, and P. Suppes, 339-65. Stanford, CA: Stanford University Press.

- 2001. After technical progress and the aggregate production function. In New developments in productivity analysis, ed. Charles R. Hulten, Edwin R. Dean, and Michael J. Harper, 173-78. Chicago: University of Chicago Press.

Triplett, Jack E. 1989. Price and technological change in a capital good: A survey of research on computers. In Technology and capital formation, ed. Dale W. Jorgenson and Ralph Landau, 127-213. Cambridge, MA: MIT Press.

Wykoff, Frank C. 2003. Obsolescence in economic depreciation from the point of view of the revaluation term. Paper presented at the NBER Summer Institute's Conference on Research in Income and Wealth, Cambridge, MA. 